\title{
Pancreaticoduodenectomy for Pancreatic Metastases of Malignant Fibrous Histiocytoma*
}

\author{
Jing Zhu, Huihua Cai", Donglin Sun \\ Department of Hepatobiliary Surgery, The First People's Hospital of Changzhou, Soochow University, \\ Changzhou, China \\ Email: \#chh1168@163.com
}

Received October 7, 2013; revised November 5, 2013; accepted November 13, 2013

Copyright (c) 2013 Jing Zhu et al. This is an open access article distributed under the Creative Commons Attribution License, which permits unrestricted use, distribution, and reproduction in any medium, provided the original work is properly cited.

\begin{abstract}
Unlike primary pancreatic carcinoma, metastases to the pancreas are rare and their resection may be performed as a palliative treatment due to poorly defined outcome. We herein present an extremely rare case of pancreatic metastases of malignant fibrous histiocytoma (MFH) undergoing pancreaticoduodenectomy with tumor-free survival within postoperative 35-month follow-up. Pancreatic resection for metastatic MFH to the pancreas should be considered in selected patients. Long-term survival or good palliation may be achieved.
\end{abstract}

Keywords: Pancreaticoduodenectomy; Pancreatic Metastasis; Malignant Fibrous Histiocytoma

\section{Introduction}

The pancreas has been found to be a rare site of metastasis with malignant tumor; the kidney, breast, lung, colon, and skin are the most common sites of the primary tumor [1]. So the quantity of literatures of pancreatic metastasis (PM) of malignant fibrous histiocytoma (MFH) is very limited and only a few cases have been reported in the world till now [2-5]. In this report we will describe a patient suffering from isolated pancreatic metastasis of $\mathrm{MFH}$, and the clinical features of the treatment. The outcomes are also discussed.

\section{Case Report}

The patient was a 69-year-old male. His past medical history showed that he had undergone lumpectomy in the left back at another hospital in May 2006, and MFH was diagnosed by pathologic examination. Unfortunately, he suffered from another two radical operation because of local recurrence on June 21, 2006 and October 31, 2006 respectively. Local radiotherapy was followed by the third operation and relapse was no longer found in the back.

He was admitted to our hospital on October 8, 2008

"Competing interest: no benefits in any form have been received or will be received from a commercial party related directly or indirectly to the subject of this article.

"Corresponding author. because of expectorated blood-tinged sputum intermittently for a month. Lower left lung mass was prompted by chest radiography and CT. The left lower pulmonary lobectomy was performed on October 13 and postoperative pathology indicated metastatic MFH (Figure 1).

Three courses of CAP (CTX/ADM/DDP) regimen chemotherapy were additionally treated after pulmonary lobectomy and the regular re-examination prompted a stable condition until June 2010. He presented abdominal pain for three days and CT indicated a tumor in the head of the pancreas. The values of serum CEA, CA 19-9, CA 15-3 were within normal laboratory range. Without contraindications, pancreaticoduodenectomy was performed on June 28, 2010, and metastatic malignant fibrous histiocytoma of the head of the pancreas was proved by postoperative pathology (Figure 1). The patient recovered from the operations without complications and has been remaining free of tumor in follow-up 35 months (Figure 2).

\section{Discussion}

Unlike primary pancreatic carcinoma, metastatic lesions to the pancreas are rare, accounting for less than $5 \%$ of all pancreatic neoplasms [6] and approximately $2 \%$ of pancreatic malignancies [1,7]. Patients with pancreatic metastases are often asymptomatic and detected incidentally or during follow-up investigations even several 

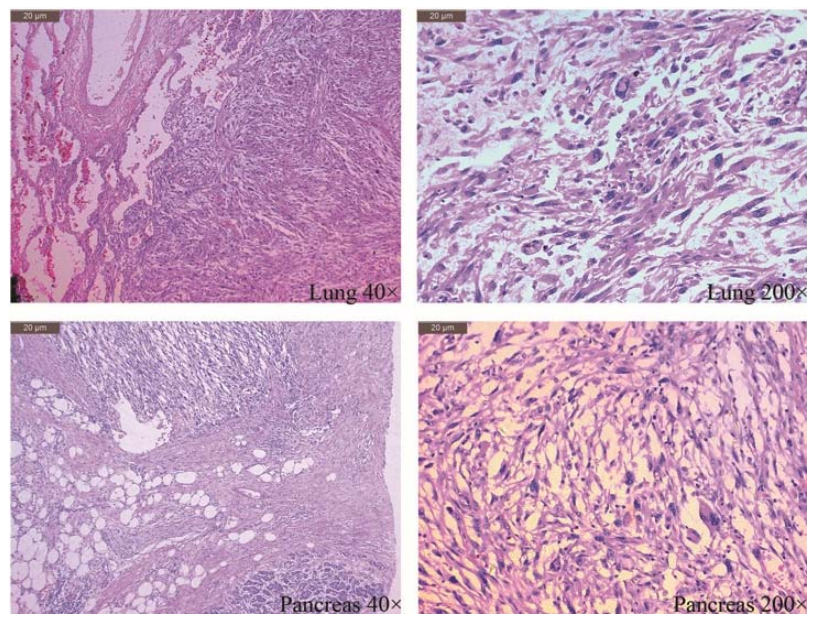

Figure 1. The cell feature of our case was a pleomorphic cell arranged in a storiform pattern. The areas of malignant fibrous histiocytoma infiltrating the pulmonary and pancreatic tissue are shown. (H\&E staining. Upper: pulmonary metastasis of MFH; Down: pancreatic metastasis of MFH).
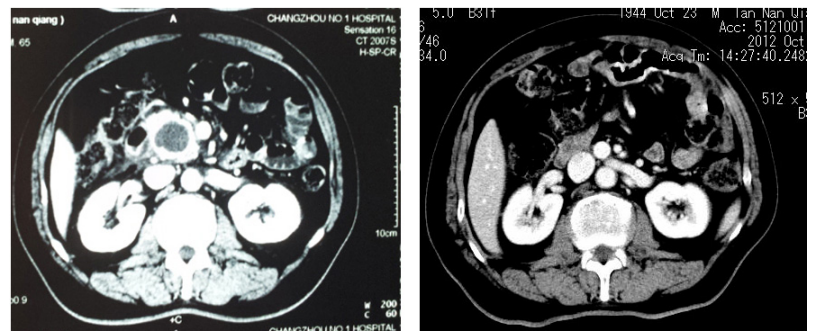

Figure 2. A computed tomography scan of the abdomen showing the tumor in the head of the pancreas (Left). No local recurrence or distant metastasis was noted during follow-up of 29 months (Right).

years after the removal of the primary tumor. The primary tumors are most commonly located in kidney, breast, lung, and colon cancers, or more rarely, gastric cancer, melanoma, and sarcoma [1,8-10].

Malignant fibrous histiocytoma (MFH) has been regarded as one of the most common sarcoma tumors in soft tissue since the introduction of the concept of facultative fibroblasts by Ozzello et al. [11] in 1963. This tumor has a high likelihood of metastasis and recurrence and the most common sites of occurrence are the upper/lower limbs, trunk followed by the chest and retroperitoneal cavity. But pancreatic metastasis secondary to MFH of is extremely uncommon. Up to date, there are a few sporadic cases reported, using a systematic Pub Med search [2-5].

However, it is still controversial whether the patients with PM should take the surgical treatment or not. But some recent literatures $[12,13]$ suggest that patients with isolated PM can benefit from surgery and pancreatic resection may achieve long-term survival or good palliation in selected cases. The surgical complications and perioperative mortality of PM have no obvious difference with that of pancreatic primary tumors. The following criteria for the selection of patients for pancreatic metastasectomy are suggested: 1) primary cancer types that are associated with successful outcomes, 2) control of the primary cancer site, 3) isolated metastases, 4) resectability of the metastasis, 5) patient fitness to tolerate pancreatectomy.

Despite the poor radiation sensitivity of MFH, radiotherapy is still the main means of adjuvant therapy to control local recurrence [14]. But the efficacy of chemotherapy is still controversial. Some researchers contended that concurrent adjuvant chemotherapy and radiotherapy might be an effective treatment for MFH [15]. However, Gutierrez [14] suggested that surgical resection and radiotherapy are unique among treatment modalities in association with a significant survival benefit, rather than chemotherapy.

\section{Conclusion}

In our experience, the patient underwent three local operations in the left inferior back and pulmonary lobectomy due to recurrence or metastasis from MFH. Resection of pulmonary metastases from sarcoma has been studied extensively and can improve long-term survival. In an independent study, the 5-year disease-free survival in similar patients was reported to be $41 \%$ [16]. Pancreas solitary metastasis occurred in more than two years after pulmonary resection. Solitary metastasis to the pancreas occurs less frequently; in fact, there are few reports concerning solitary resectable metastatic tumors of the pancreas. In the Mayo clinic series [10], only 27 out of 1357 patients (2\%) with solitary pancreatic masses had secondary pancreatic tumor, and only four of them were resected. Pancreaticoduodenectomy was performed in our patient successfully. He recovered from operation without complications and remains free of tumor within 35month follow-up. Surgical resection has been regarded as the best therapeutic option to improve the long-term survival of patients with isolated pancreatic metastasis. Adjuvant radiotherapy is still a helpful tool to control local recurrence. The clinical effect of chemotherapy needs to be verified in further research.

\section{REFERENCES}

[1] S. Reddy and C. L. Wolfgang, "The Role of Surgery in the Management of Isolated Metastases to the Pancreas," The Lancet Oncology, Vol. 10, No. 3, 2009, pp. 287-293. http://dx.doi.org/10.1016/S1470-2045(09)70065-8

[2] C. Sperti, C. Pasquali, G. Liessi, L. Pinciroli, G. Decet and S. Pedrazzoli, "Pancreatic Resection for Metastatic Tumors to the Pancreas," Journal of Surgical Oncology, Vol. 83, No. 3, 2003, pp. 161-166.

http://dx.doi.org/10.1002/jso.10262 
[3] Y. Shinagawa, T. Suzuki, Y. Hamanaka, K. Nishihara and M. Takahasi, "Solitary Pancreatic Metastasis of Malignant Fibrous Histiocytoma Treated by Distal Pancreatectomy,” Pancreas, Vol. 7, 1992, pp. 726-730. http://dx.doi.org/10.1097/00006676-199211000-00015

[4] T. Akatsu, M. Shimazu, T. Morii, H. Morioka, H. Yabe and M. Kitajima, "Pancreatic Metastasis from Musculoskeletal Sarcoma: A Case Report with Malignant Fibrous Histiocytoma and Review of the Literature," Digestive Diseases and Sciences, Vol. 52, No. 8, 2007, pp. 1958-1963. http://dx.doi.org/10.1007/s10620-006-9424-6

[5] M. M. Ho, T. J. Howard and K. D. Lillemoe, "Can Pancreaticoduodenectomy Be Used to Palliate Selective Metastatic Malignancies? Case Report of Malignant Fibrous Histiocytoma,” Journal of Gastrointestinal Surgery, Vol. 9, No. 7, 2005, pp. 934-937. http://dx.doi.org/10.1016/j.gassur.2005.04.014

[6] G. C. Sotiropoulos, H. Lang, C. Liu, E. I. Brokalaki, E. Molmenti and C. E. Broelsch, "Surgical Treatment of Pancreatic Metastases of Renal Cell Carcinoma,” JOP: Journal of the Pancreas, Vol. 6, No. 4, 2005, pp. 339343.

[7] H. Medina-Franco, N. B. Halpern and J. S. Aldrete, "Pancreaticoduodenectomy for Metastatic Tumors to the Periampullary Region,” Journal of Gastrointestinal Surgery, Vol. 3, No. 2, 1999, pp. 119-122. http://dx.doi.org/10.1016/S1091-255X(99)80019-5

[8] E. Nakamura, M. Shimizu, T. Itoh and T. Manabe, "Secondary Tumors of the Pancreas: Clinicopathological Study of 103 Autopsy Cases of Japanese Patients,” Pathology International, Vol. 51, No. 9, 2001, pp. 686-690. http://dx.doi.org/10.1046/j.1440-1827.2001.01258.x

[9] T. Belagyi, P. Zsoldos, R. Makay, A. Issekutz and A. Olah, "Multiorgan Resection (Including the Pancreas) for Metastasis of Cutaneous Malignant Melanoma," JOP: Journal of the Pancreas, Vol. 7, No. 2, 2006, pp. 234240.

[10] J. M. Alamo, F. Pareja, M. A. Gomez, I. Alarcon, C. Ber- nardos, L. Barrera, et al., "Obstructive Jaundice Secondary to Pancreatic Metastases of a Soft-Tissue Sarcoma," Revista Espanola de Enfermedades Digestivas, Vol. 99, No. 9, 2007, pp. 557-559.

[11] L. Ozzello, A. P. Stout and M. R. Murray, "Cultural Characteristics of Malignant Histiocytomas and Fibrous Xanthomas,” Cancer, Vol. 16, No. 3, 1963, pp. 331-344. http://dx.doi.org/10.1002/1097-0142(196303)16:3<331:: AID-CNCR2820160307>3.0.CO;2-F

[12] S. Crippa, C. Angelini, C. Mussi, C. Bonardi, F. Romano, P. Sartori, et al., "Surgical Treatment of Metastatic Tumors to the Pancreas: A Single Center Experience and Review of the Literature,” World Journal of Surgery, Vol. 30, No. 8, 2006, pp. 1536-1542. http://dx.doi.org/10.1007/s00268-005-0464-4

[13] S. Eidt, M. Jergas, R. Schmidt and M. Siedek, "Metastasis to the Pancreas-An Indication for Pancreatic Resection?” Langenbeck's Archives of Surgery, Vol. 392, No. 5, 2007, pp. 539-542. http://dx.doi.org/10.1007/s00423-007-0148-7

[14] J. C. Gutierrez, E. A. Perez, D. Franceschi, F. L. Moffat, Jr., A. S. Livingstone and L. G. Koniaris, "Outcomes for Soft-Tissue Sarcoma in 8249 Cases from a Large State Cancer Registry,” The Journal of Surgical Research, Vol. 141, No. 1, 2007, pp. 105-114. http://dx.doi.org/10.1016/j.jss.2007.02.026

[15] D. Krikelis and I. Judson, "Role of Chemotherapy in the Management of Soft Tissue Sarcomas," Expert Review of Anticancer Therapy, Vol. 10, No. 2, 2010, pp. 249-260. http://dx.doi.org/10.1586/era.09.176

[16] A. N. van Geel, U. Pastorino, K. W. Jauch, I. R. Judson, F. van Coevorden, J. M. Buesa, et al., "Surgical Treatment of Lung Metastases: The European Organization for Research and Treatment of Cancer-Soft Tissue and Bone Sarcoma Group Study of 255 Patients,” Cancer, Vol. 77, No. 4, 1996, pp. 675-682. http://dx.doi.org/10.1002/(SICI)1097-0142(19960215)77: 4<675::AID-CNCR13>3.0.CO;2-Y 